\title{
Development of diaphragm connector elements for three-dimensional nonlinear dynamic analysis of precast concrete structures
}

Dichuan Zhang, Robert Fleischman, Clay J. Naito, Zhi Zhang

- School of Engineering

\begin{abstract}
Diaphragm connector elements were developed for three-dimensional finite element models of precast concrete structures used in nonlinear time history analyses. The use of discrete elements for the diaphragm connectors permits the direct evaluation of local force and deformation demands, information needed in calibrating design factors for a new diaphragm seismic design methodology. This article describes the element formulation. The connector elements consist of assemblages of standard elements readily available in most finite element software libraries. The connector element calibration is based on full-scale testing of common precast diaphragm connectors. In these tests, the connector exhibited hysteretic pinching, stiffness/strength degradation, and slip mechanisms. The diaphragm connector elements were constructed to capture these behaviors to an accuracy sufficient for establishing viable design factors, while still appropriate for insertion into large degree-of-freedom models. The models are validated against the results of simulation-driven tests for critical precast diaphragm joints and a half-scale shake table test.
\end{abstract}

Original language

Pages (from-to)

Number of pages

Journal

Volume

Issue number

State
English

$187-202$

16

Advances in Structural Engineering

19

2

Published - Feb 12016

Zhang, D., Fleischman, R., Naito, C. J., \& Zhang, Z. (2016). Development of diaphragm connector elements for three-dimensional nonlinear dynamic analysis of precast concrete structures. Advances in

DOI: $10.1177 / 1369433215624319$ Structural Engineering, 19(2), 187-202. 